\title{
Total productivity change of Health Centers in Greece in 2016-2018: a Malmquist index data envelopment analysis application for the primary health system of Greece
}

\author{
Anastasios Trakakis $^{1 *} \mathbb{1}$, Miltiadis Nektarios ${ }^{2}$, Styliani Tziaferi $^{1}$ and Panagiotis Prezerakos ${ }^{1}$
}

\begin{abstract}
Background: This paper attempts to evaluate the primary health care system by evaluating health centres in Greece. Methods: Malmquist Index Data Envelopment Analysis is applied to study the total productivity of 155 health centres in Greece during 2016-2018. The data were collected from the Ministry of Health and submitted to quality tests to ensure validity and avoid bias.

Results: This paper measures the productivity of each of the 155 health centres in Greece and how it shifted during 2016-2018. In addition, the overall productivity change of the 155 health centres over time is calculated and analysed as being due to technical efficiency or technological efficiency. The analysis of the mean values showed a decrease of $0.9 \%$ in the overall productivity factor from 2016 to 2017 and a decrease of 5.2\% from 2017 to 2018 . The overall decrease in the productivity of the 155 health centres was 3.1\%. From 2016 to 2018, 59 health centres changed their productivity mainly due to technological change and 91 changed mainly due to technical efficiency change. One health centre showed regression to its total productivity due to equal regression of its technical efficiency and technology.

Conclusions: The method used is nonparametric data envelopment analysis along with the Malmquist index to include panel data in the analysis. Meaningful results were extracted by indicating the number of health centres that improved their productivity, regressed in productivity, or remained constant through the period 2016-2018. This paper may contribute to improving health centres' efficiency and productivity. Furthermore, valuable results can be extracted for the National Health Care System to match available resources that correspond to each health centre's needs, as well as for manager planners and stakeholders in primary health care.
\end{abstract}

Keywords: Health Centre's Total Productivity, Data envelopment analysis, Malmquist productivity index, Internal and External Validity, Primary Health Care

JEL Classification: C14, C32, C52, 110

*Correspondence: anast.trak@gmail.com

${ }^{1}$ Faculty of Health Sciences, University of Peloponnese, Tripoli, Greece

Full list of author information is available at the end of the article

\section{Background}

Primary health care has recently received more attention, as the World Health Organization (WHO) has called attention to its importance to the population's overall health and its contribution to the National Health System of every country. Every country in the OECD participates original author(s) and the source, provide a link to the Creative Commons licence, and indicate if changes were made. The images or other third party material in this article are included in the article's Creative Commons licence, unless indicated otherwise in a credit line to the material. If material is not included in the article's Creative Commons licence and your intended use is not permitted by statutory regulation or exceeds the permitted use, you will need to obtain permission directly from the copyright holder. To view a copy of this licence, visit http://creativecommons.org/licenses/by/4.0/. The Creative Commons Public Domain Dedication waiver (http://creativeco mmons.org/publicdomain/zero/1.0/) applies to the data made available in this article, unless otherwise stated in a credit line to the data. 
in a strategy that focuses on strengthening primary health care, as stated by WHO at Alma-Ata in 1978. OECD countries, including Greece, attempted to monitor primary health care to follow the strategy imposed by the WHO [1].

In 2013, the health care expenditures in Greece were higher than the average expenditures of OECD Countries by $0.3 \%$. The economic crisis led to funding cuts in health care services, reducing health care expenditures below the average of OECD countries by $1.8 \%$ in 2017 , intensifying the inadequate primary health care system and delivery of health care services [2-4]. The lack of health promotion, disease prevention, and rehabilitation as well as the dissatisfaction of people receiving health services indicate distribution problems in health services, problematic administration, and low productivity. This is mainly due to the inadequacy of primary health care, which highlights the importance of its contribution to the whole health care system and the efforts that should be made to strengthen it [5-7]. Moreover, the necessity of a stronger and integrated primary health care system is indicated by the fact that Greece faces one of the highest rates of chronic diseases among the EU-27, as well as one of the highest overall household health expenditures [8].

The economic crisis of the last decade in Greece was accompanied by funding cuts for the National Health System. The bailout program by international creditors and the three Economic Adjustment Programs led to additional funding cuts for the public sector and Primary Health Care System between 2010 and 2018 [9]. To overcome the negative effects of funding cuts while strengthening the National Health System, reforms were introduced. Emphasis was placed on primary health care and its contribution to the population's overall health. The national strategy of the reform involved establishing the National Primary Health Care Networks (PEDY) in 2014. All public Primary Health Care services were transferred to PEDY and coordinated by Regional Health Authorities (ESY), which was established to create a two-pillar system from 2017 to 2020. Law 4486/2017 introduced the reform of primary health care, including radical changes with the establishment of local health units (TOMY) and contracted family doctors, as the first point of providing health services and guiding people through the health system. The new primary health care model focuses on prevention, health promotion, and integrated care $[8,9]$.

The reform included establishing 239 TOMYs representing the first pillar of primary health care and the upgradation of health centres representing the second pillar of primary health care. Therefore, health centres would include more complex health services. Moreover, each TOMY would be under the supervision of a corresponding health centre. This reform is based on the principles of primary health care and aims to establish an integrated model of the primary health care system [9]. Eventually, 127 TOMYs opened, which were mostly concentrated in mainland Greece. Therefore, rural areas were barely covered, while the urban population bypassed TOMY with direct access to hospitals or the private sector [8].

This paper attempts to evaluate the efficiency of health centres in Greece during the years of the major reform, which coincided with the last years of economic adjusted programs.

Health centres are one of the main compounds of primary health systems. By attempting to evaluate their productivity and efficiency, important information would be brought to light regarding primary health care in Greece. In 2016-2018, 207 health centres were operating in Greece, of which 155 were submitted for this paper's analysis. The other 52 health centres were excluded due to lack of data to avoid random estimation and possibility of bias. Out of the 155 health centres, 9 were operating in the provision of Attica, which is the main urban area of Greece. In addition, 5 health centres were operating in semiurban areas. All the other health centres submitted to the paper's analysis were operating in rural areas (90\%).

\section{Method}

There are two approaches to measuring efficiency according to the relevant literature, parametric and nonparametric. Nonparametric approaches are most commonly used in health care studies since they have the advantage that the functional form does not need to be known [10]. The most commonly used nonparametric approach is data envelopment analysis (DEA) [11]. Moreover, DEA has the advantage of handling multiple inputs and outputs and is used with any input-output measurement. In studies measuring health care efficiency, DEA is the most commonly used method [12].

Farrell (1957), based on Debreu (1951) and Koopmans (1951), first introduced modern efficiency and attempted to measure the efficiency of a firm by considering multiple inputs $[13,14]$. Farrell analysed and divided the efficiency measured into two components, technical and allocative efficiency, both of which appraise economic efficiency [15].

Charnes, Cooper and Rhodes (CCR, 1978), based on Farrell, proposed the DEA model. DEA is a linear programming method that constructs a nonparametric frontier containing all the firms submitted for analysis to measure their efficiencies. The firms are called decisionmaking units (DMUs), and their data, translated as inputs and outputs, are used to measure their efficiencies. The 
constructed frontier includes all efficient DMUs, while below the frontier, all inefficient DMUs are placed. Technical efficiency depends on the "input-output ratio of productivity" [16] and can be divided into pure technical and scale efficiency. Essentially, technical efficiency refers to converting inputs into outputs according to best practice so that the DMU is as efficient as possible [2].

Technical efficiency measured by DEA has two orientations according to the relevant literature. The input orientation of DEA binds the outputs produced to solve a linear programming equation that minimizes the inputs used. In contrast, the output orientation of DEA binds the inputs used to solve a linear programming equation that maximizes the outputs produced [10, 17].

In addition, two methods of DEA have been proposed: the first is based on the assumption of constant return to scale (CRS), as was introduced by Charnes, Cooper and Rhodes (CCR, 1978), while the other is based on the assumption of a variable return to scale (VRS), as later introduced by Banker, Charnes and Cooper in 1984. "The CRS method is applied when all DMUs are operating at an optimal level while under imperfect competition, the VRS method is applied considering that not all DMUs are operating at an optimal level, assuming that there are scale efficiencies" $[18,19]$.

CRS and VRS DEA can each measure the technical efficiencies of the DMUs included in the analysis, but they are not able to utilize panel data, means they are not able to measure the impact of time on the efficiencies. To overcome this limitation, the Malmquist productivity index (MPI) can be used along with the DEA. The MPI was first introduced by Caves et al. (1982), who relied on Shephard's (1970) distance function to measure the productivity change over time and divide it into change due to technology and technical efficiency [20].

Productivity is defined as the ratio of an index of outputs over an index of inputs used to produce them [2123]. Increasing productivity means that more outputs are obtained from the same amount of inputs, or fewer inputs are required to produce the same output. The change in productivity over time is called productivity change and shifts over time due to technical efficiency and technical/technological change [2, 15, 24-26].

MPI DEA is essentially a nonparametric mathematical programming approach, which, according to the literature, is the most widely used method to include panel data in the analysis and calculate the indices of total factor productivity, technical efficiency, and its components (pure technical efficiency and scale efficiency) and technological change over time [2]

There are many applications of MPI DEA in health care studies. In Greece, Xenos et al. [27] measured the efficiency and productivity assessment of public hospitals in
Greece during the crisis period 2009-2012. Additionally, Dimas et al. [11] measured productivity performance and its components in Greek public hospitals. In contrast, Androutsou et al. [2] measured efficiency and productivity across hospitals in the Regional Health Authority of Thessaly, Greece. Fragkiadakis et al. [28] measured the operational and economic efficiency of public hospitals in Greece. In contrast, this study, although it uses MI DEA, focuses on primary health care in Greece, which has recently gained more interest, and there is a lack of applications measuring its efficiency and productivity.

In this paper, the input-oriented MPI DEA is used. The first reason for this is because in the health sector, it is impossible to predefine outputs, but inputs can be predefined and controlled. Second, MPI DEA is used because panel data are included in the paper [29-31].

\section{Model specification-data envelopment analysis and Malmquist productivity index}

The mathematical concepts of DEA and MPI are briefly analysed below since the aim of this paper is to evaluate the productivity and efficiency of the 155 health centres in Greece during 2016-2018. An extended mathematical analysis of the methods of DEA and MPI and how they are used is presented in the relevant literature.

Before presenting the mathematical background of MPI, DEA will be analysed. The mathematical analysis refers to an input-oriented DEA under the CRS and VRS assumptions, since both are needed to estimate MPI.

In the input-oriented mathematical model of CRS, it is assumed that there are "N DMUs that use $\mathrm{K}$ inputs to produce $\mathrm{M}$ outputs. Under this assumption, there are two matrices, the $\mathrm{K}^{*} \mathrm{~N}$ input matrix, referred to as the $\mathrm{X}$, and the $\mathrm{M}^{*} \mathrm{~N}$ output matrix, referred to as $\mathrm{Y}$, which both represent the data of all N DMUs" [32]. To measure the efficiency of the DMU, the literature considers the calculation of the ratio of all outputs over all inputs. T.J. Coelli presented the following mathematical linear programming problem in 1996:

“ $\min _{\theta, \lambda} \theta$,

s.t.

$-\mathrm{y}_{\mathrm{i}}+\mathrm{Y} \lambda \geq 0$,

$\theta \mathrm{x}_{\mathrm{i}}-\mathrm{X} \lambda \geq 0$,

$\lambda \geq 0$.

The symbol $\theta$ is a scalar, and $\lambda$ is an $\mathrm{N}^{*} 1$ vector of constants" [32]. The symbol $\theta$ represents the efficiency of the DMUs, and their values are within a closed interval of $(0,1)$. The problem aims to compute the values of $\theta$. Values of 1 mean that the DMU operates at an optimal level of efficiency, while values less than 1 mean the DMUs performance is inefficient. The mathematical function has to be solved $\mathrm{N}$ times for each DMU [32]. 
The CRS model is based on the assumption that all DMUs operate at an optimal scale. In contrast, the VRS model avoids this assumption, because there might be scale efficiencies. By adding the constraint $\mathrm{N} 1^{\prime} \lambda=1$ to the CRS model, scale efficiency effects are calculated, and technical efficiency is divided into pure technical efficiency and scale efficiency for each DMU [19]. N1 represents an $\mathrm{N}^{*} 1$ vector of ones [32].

The MPI is an extended application of DEA to measure productivity change over time for each DMU and analyse it into change owing to technical efficiency and change owing to technology [32].

MPI DEA is used for panel data, and there is no need to choose between the CRS or VRS approach since they give the same results. In estimating the MPI DEA, both the CRS and VRS approaches are used to calculate the various distances that construct the Malmquist indices [33].

There are two orientations for the MPI DEA method: input and output orientations. In the input orientation, the production is described by calculating the minimal proportional decrease of the input vector, given the output vector. In contrast, in the output orientation, the production is described by calculating the maximal proportion increase of the output vector, given the input vector [34].

In this paper, panel data for three years (2016-20172018) are considered, forming two periods (2016-2017 and 2017-2018). The calculation of MPI involves the estimation of four distances for each of the two periods. DEA analysis by CRS and VRS assumptions is performed for each of the three years (2016, 2017 and 2018), measuring the efficiencies of the DMUs. Note that although the efficiencies of the DMUs for 2016 are calculated, Malmquist indices cannot be estimated, as no data are available for 2015.

The Malmquist index was first introduced in 1970 with Shephard's distance function and has since been widely used in many areas where efficiency needs to be measured with panel data. Färe specified an output-oriented MPI in 1994 [35]. In this paper, the input-oriented MPI is used.

The MPI for a period ( $t$ to $t+1$ ) represents the productivity at the production point $\left(\mathrm{x}_{\mathrm{t}+1}, \mathrm{y}_{\mathrm{t}+1}\right)$ relative to the production point $\left(x_{t}, y_{t}\right)$ for each DMU.

"M $\left(y_{t+1}, x_{t+1}, y_{t}, x_{t}\right)=\left\{\left[d^{t+1}\left(x_{t+1}, y_{t+1}\right) / d^{t}\left(x_{t}, y_{t}\right)\right]^{*}\left[\left(d^{t}\right.\right.\right.$ $\left.\left.\left(x_{t}, y_{t}\right) / d^{t+1}\left(x_{t}, y_{t}\right) *\left(d^{t}\left(x_{t+1}, y_{t+1}\right) / d^{t+1}\left(x_{t+1}, y_{t+1}\right)\right)\right]^{1 / 2}\right\}^{\prime}$ $[24,32,35,36]$.

The first fraction of the equation represents technical efficiency change, while the second fraction represents technology change for the period ( $t$ to $t+1)$. Moreover, technical efficiency change can be further analysed into change due to pure technical efficiency and scale inefficiency. Positive total productivity growth from time $\mathrm{t}$ to time $\mathrm{t}+1$ means a value greater than one for the index $[24,32,35,36]$.

To calculate the MPI equation, the four distances mentioned above must be calculated by linear programming methods.

1. $\left[d^{t}\left(x_{t}, y_{t}\right)\right]^{-1}=\min _{\theta, \lambda} \theta$, s.t. $-y_{i t}+Y_{t} \lambda \geq 0, \theta x_{i t}-X_{t} \lambda \geq 0$, $\lambda \geq 0$

2. $\left[\mathrm{d}^{\mathrm{t}+1}\left(\mathrm{x}_{\mathrm{t}+1}, \mathrm{y}_{\mathrm{t}+1}\right)\right]^{-1}=\min _{\theta, \lambda} \theta$, s.t. $-\mathrm{y}_{\mathrm{i}, \mathrm{t}+1}+\mathrm{Y}_{\mathrm{t}+1} \lambda \geq 0$, $\theta \mathrm{x}_{\mathrm{i}, \mathrm{t}+1}-\mathrm{X}_{\mathrm{t}+1} \lambda \geq 0, \lambda \geq 0$

3. $\left[d^{t}\left(x_{t+1}, y_{t+1}\right)\right]^{-1}=\min _{\theta, \lambda} \theta$, s.t. $-y_{i, t+1}+Y_{t} \lambda \geq 0$, $\theta x_{i, t+1}-X_{t} \lambda \geq 0, \lambda \geq 0$

4. $\left[\mathrm{d}^{\mathrm{t}+1}\left(\mathrm{x}_{\mathrm{t}}, \mathrm{y}_{\mathrm{t}}\right)\right]^{-1}=\min _{\theta, \lambda} \theta$, s.t. $-\mathrm{y}_{\mathrm{i}, \mathrm{t}}+\mathrm{Y}_{\mathrm{t}+1} \lambda \geq 0, \theta \mathrm{x}_{\mathrm{i}, \mathrm{t}^{-}}$ $X_{t+1} \lambda \geq 0, \lambda \geq 0$

Note that in this paper, $\mathrm{N}(3 \mathrm{~T}-2)$ linear programming equations must be calculated [30, 34]. Considering the 155 health centres and the 2 time periods that were included in the analysis, 620 linear programming equations need to be calculated.

\section{Data}

Efforts were made to include all health centres of Greece in the analysis of this paper, but due to lack of data, only 155 health centres were included. Fifty-two health centres were excluded to avoid random estimation and the possibility of bias.

The sample used for the analysis of this paper is homogenous, as it includes the majority of health centres of Greece $(74.87 \%$ of the total), distributed across the seven health regions of Greece. Out of the 155 health centres, 9 were operating in Attica, which is the main urban area of Greece. In addition, 5 health centres were operating in semiurban areas. All the other health centres submitted to the paper's analysis were operating in rural areas (90\%). The 155 health centres use the same categories of inputs, generating the same categories of outputs, differing only in the quantities used. This ensures comparability and validates this paper in measuring the health centres' productivity and efficiencies for the years 2016, 2017, 2018 with DEA. Furthermore, according to the literature, the requirements for conducting MPI DEA are satisfied, ensuring meaningful results. These requirements include that at least one DMU in the sample consumes and produces each input and output and that each DMU in the sample consumes at least one input and produces at least one output [37, 38]. By including the majority of health centres in Greece, discriminatory power between the efficient and inefficient units is also achieved $[39,40]$.

In the analysis of this paper, 12 outputs were included to measure the change in productivity and the change in 
technical efficiency and technology of each health centre. The outputs represent the total health care services provided by each health centre:

(1) Total number of "Nursing Operations" appliedOutput1

(2) Total Number of "Microsurgeries" applied-Output2

(3) Total Number of "Dental Procedures" appliedOutput3

(4) Total number of "Chronic disease cases" facedOutput4

(5) Total number of "Emergencies" faced-Output5

(6) Total Number of "Regular Incidents" facedOutput6

(7) Total Number of "Urgent Incidents" faced-Output7

(8) Total Number of "Transcriptions" given-Output8

(9) Total Number of "Biopathological and Laboratory exams" applied-Output9

(10) Total Number of "Test Mantoux" applied-Output10

(11) Total Number of "Vaccinations for adults" applied-Output11

(12) Total Number of "Vaccinations for kids and teenagers" applied-Output12

In contrast, 4 inputs were used, representing the total staff employed and occupied in the health centres:

(13) Total "Number of Managers" employed-Input1

(14) Total "Number of Doctors" employed-Input2

(15) Total "Number of Nursing Staff" employedInput3

(16) Total "Number of non-medical staff" employedInput4

All inputs and outputs used for this paper are for the years 2016, 2017 and 2018. In Additional File 1, a table is presented, which shows the descriptive statistics of all inputs and outputs used to evaluate the total productivity and efficiency of each of the 155 health centres included in the analysis of this paper. The descriptive statistics show the minimum, maximum and mean values, as well as the standard deviation of each input and output included in the analysis.

\section{Results}

\section{Productivity}

The productivity and efficiency of each of the 155 health centres were measured by performing input-oriented MPI DEA using the DEAP ver2.1 program.

The summary table with the results of technical efficiencies under the CRS and VRS assumptions for 2016, 2017, and 2018 of all DMUs included in the analysis is presented below (Table 1).

The Spearman's rank correlation coefficient between the efficiencies calculated under the CRS and VRS assumptions is calculated for each year to interpret the correlation between the various rankings given by CRS and VRS to determine the degree of association between the 2 methods [41] (Table 2).

For 2016, 2017, and 2018, the correlation coefficients are $0.571,0.698$, and 0.665 , respectively. The statistically significant coefficients show a high degree of correlation between the CRS and VRS methods for each year.

\section{Malmquist productivity index}

The results for the 2016-2017 and 2017-2018 periods, as well as the overall results for the period 2016-2018, are presented in Additional File 2 for all the firms included in the analysis. Effch, techch, pech, sech and tfpch columns represent the indices related to efficiency change, technological change, pure technical efficiency change, scale efficiency change and total factor productivity change, respectively. Indices with values greater than one indicate progress for the health centres, values less than one indicate decline, and values equal to one indicate no change from $t$ to $t+1$ [34].

Table 3 shows summary statistics for all DMUs with their mean, minimum and maximum values, the Standard Deviation of effch, techch, and tfpch under each of the two periods, and the overall results for both periods.

Table 1 Descriptive statistics, mean, maximum, minimum and standard deviation of the efficiencies in each year, under CRS and VRS assumption for the 155 DMU's

\begin{tabular}{lllllll}
\hline & YEAR1-crs & YEAR1-vrs & YEAR2-crs & YEAR2-vrs & YEAR3-crs & YEAR3-vrs \\
\hline Mean & 0.85419 & 0.94366 & 0.85128 & 0.92827 & 0.85074 & 0.93104 \\
Std. Deviation & 0.203580 & 0.134536 & 0.210957 & 0.149666 & 0.197387 & 0.139425 \\
Minimum & 0.195 & 0.318 & 0.274 & 0.307 & 0.317 & 0.333 \\
Maximum & 1.000 & 1.000 & 1.000 & 1.000 & 1.000 & 1.000 \\
\hline
\end{tabular}

$\mathrm{N}$ : 155, Valid: 155, Missing: 0 
Table 2 Spearman-rank correlations between input-oriented crste and vrste models

\begin{tabular}{lll}
\hline Year 2016 & & \\
\hline & YEAR1 CRS & YEAR1 VRS \\
\hline YEAR1_CRS & 1.000 & $0.571^{* *}$ \\
YEAR1 VRS & $0.571^{* *}$ & 1.000 \\
\hline Year 2017 & & YEAR2 VRS \\
\hline & YEAR2 CRS & $0.698^{* *}$ \\
\hline YEAR2_CRS & 1.000 & 1.000 \\
YEAR2 VRS & $0.698^{* *}$ & 1 \\
\hline Year 2018 & & YEAR3 VRS \\
\hline & YEAR3 CRS & $0.665^{* *}$ \\
\hline YEAR3_CRS & 1.000 & 1.000 \\
YEAR3 VRS & $0.665^{* *}$ & \\
\hline
\end{tabular}

${ }^{* *}$ Correlation is significant at the 0.01 level (2-tailed). N:155

Table 3 Arithmetic mean, minimum, maximum and St. deviation of effch, techch, tfpch of each period for all DMU's

\begin{tabular}{llll}
\hline & effch_2016_2017 & effch_2017_2018 & effch_mean \\
\hline Arithmetic mean & 1.02483 & 1.04426 & 1.01459 \\
Std. Deviation & 0.283444 & 0.328508 & 0.182204 \\
Minimum & 0.336 & 0.323 & 0.600 \\
Maximum & 3.256 & 3.430 & 2.197 \\
\hline & techch_2016_2017 & techch_2017_2018 & techch_mean \\
\hline Arithmetic mean & 1.01713 & 0.96447 & 0.97400 \\
Std. Deviation & 0.220324 & 0.209529 & 0.104796 \\
Minimum & 0.580 & 0.270 & 0.609 \\
Maximum & 2.413 & 2.155 & 1.446 \\
\hline & tfpch_2016_2017 & tfpch_2017_2018 & tfpch_mean \\
\hline Arithmetic mean & 1.04 .688 & 1.00 .658 & .99 .263 \\
Std. deviation & 0.374496 & 0.379603 & 0.234574 \\
Minimum & 0.213 & 0.270 & 0.501 \\
Maximum & 3.424 & 3.627 & 2.420 \\
\hline
\end{tabular}

$\mathrm{N}$ : 155, Valid: 155, Missing: 0

In overall productivity change, Health Centre 22 has the maximum improvement, while Health Centre 120 has the maximum decline.

Table 4 shows the geometric mean of total productivity for the 155 health centres over 2016-2017 and 20172018 and the geometric mean values of efficiency, divided into technical and scale efficiency, and technology. The table also presents the number of health centres whose productivity increased, decreased, or remained constant over the two periods.

In the first period (2016-2017), 73 health centres achieved progress in their total productivity, while 82 had lower productivity levels. In the second period, 72 health centres achieved progress in their total productivity, while 83 had lower productivity levels. Overall productivity for both periods showed an increase for 61 health centres and a decrease for 94 health centres.

After monitoring the productivity change of each health centre, the factor that contributed mainly to the change was explained (Table 5).

In the first period (2016-2017), 48 health centres showed improvement in their technical efficiency, 43 showed a decline in their technical efficiency, and 64 achieved the same levels of technical efficiency. In addition, 74 health centres improved their technology, while 81 showed a decline in their technology. In the second 
Table 4 Summary scores and number of health centres that progressed, regressed, or remained constant

\begin{tabular}{llll}
\hline Geometric Mean & $\mathbf{2 0 1 6 - 2 0 1 7}$ & $\mathbf{2 0 1 7 - 2 0 1 8}$ & Total (2016-2018) \\
\hline effch & 0.994 & 1.007 & 1.000 \\
techch & 0.997 & 0.941 & 0.969 \\
pech & 0.980 & 1.006 & 0.993 \\
sech & 1.014 & 1.001 & 1.008 \\
tfpch & 0.991 & 0.948 & 0.969 \\
DMU's that progressed (tfpch> 1) & $73(47.09 \%)$ & $72(46.45 \%)$ & $61(39.35 \%)$ \\
DMU's that regressed (tfpch<1) & $82(52.9 \%)$ & $83(53.54 \%)$ & $94(60.64 \%)$ \\
DMU's remained constant (tfpch=1) & 0 & 0 & 0
\end{tabular}

Table 5 Summary results, number of progressed, regressed or remained constant Health Centers

\begin{tabular}{|c|c|c|c|}
\hline PERIOD & 2016-2017 & $2017-2018$ & Total (2016-2018) \\
\hline \multicolumn{4}{|l|}{ Change into effch } \\
\hline Prog. (effch > 1) & $48(30.96 \%)$ & $43(27.74 \%)$ & $51(32.90 \%)$ \\
\hline Reg. (effch<1) & $43(27.74 \%)$ & $44(28.38 \%)$ & $46(29.67 \%)$ \\
\hline Constant (effch $=1)$ & $64(41.29 \%)$ & $68(43.87 \%)$ & $58(37.41 \%)$ \\
\hline \multicolumn{4}{|l|}{ Change into techch } \\
\hline Prog. (techch > 1) & $74(47.74 \%)$ & $62(40 \%)$ & $54(34.83 \%)$ \\
\hline Reg. $($ techch < 1) & $81(52.25 \%)$ & $93(60 \%)$ & $101(65.16 \%)$ \\
\hline Constant $($ techch $=1)$ & 0 & 0 & 0 \\
\hline \multicolumn{4}{|l|}{ Change into tfpch } \\
\hline Prog. (tfpch > 1) & $73(47.09 \%)$ & $72(46.45 \%)$ & $61(39.35 \%)$ \\
\hline Reg. (tfpch < 1) & $82(52.9 \%)$ & $83(53.54 \%)$ & $94(60.64 \%)$ \\
\hline Constant (tfpch $=1)$ & 0 & 0 & 0 \\
\hline
\end{tabular}

period (2017-2018), 43 health centres showed improvement in their technical efficiency, 44 showed a decline in their technical efficiency, and 68 achieved the same levels of technical efficiency. In addition, 62 health centres showed technology improvement, while 93 health centres showed a decline in their technology for the second period.

The analysis of the mean values showed a decrease of $0.9 \%$ in the overall productivity factor from 2016 to 2017 and a decrease of $5.2 \%$ from 2017 to 2018 . The overall decrease in the productivity of the 155 health centres was $3.1 \%$.

To examine the change in total productivity, the difference between effch and techch for each health centre is calculated. Positive values for the difference mean that the change in productivity is mainly due to a change in technical efficiency, while negative values for the difference mean that productivity change is mainly due to a change in technology for a given health centre [42].

Moreover, since effch $=$ pech"sech, if pech $>$ sech is true, then the change in technical efficiency is mainly due to pure technical efficiency progress or regression.
In contrast if it is false, then the change in technical efficiency is mainly due to the change in scale efficiency for a given health centre.

From 2016 to 2018, 59 health centres changed their productivity mainly due to technological change, 91 mainly due to technical efficiency change, while one health centre showed regression to its total productivity due to equal regression of its technical efficiency and technology.

It should be stated that the majority of health centres changed their productivity over time due to technical efficiency change and that the health centres with high volatility in their productivity had high volatility in their technology, which shows that the largest changes in productivity were mostly due to technology change. This explains why, in Fig. 1, when the mean productivity and the mean technology change over time, the changes through the 2 periods show a similar movement.

\section{Model validation}

To test the internal and external validity of the MPI DEA input-oriented model, the Spearman's rank correlation test was performed. Internal validity compares whether there are differences in the overall productivity of health centres when different inputs and outputs are used. In contrast, external validity compares whether there is consistency based on data from different periods. DEA is a nonparametric method, so it is not possible to directly compare productivity and efficiency by different models. However, the comparison of efficiencies and productivity can be applied through nonparametric correlation tests [43-46].

The total productivities of health centres were calculated using different models with different inputs and outputs. The models are presented in Table 6, which shows the different inputs and outputs used to calculate each model's efficiencies, as well as the total productivities of the health centres by each model. 


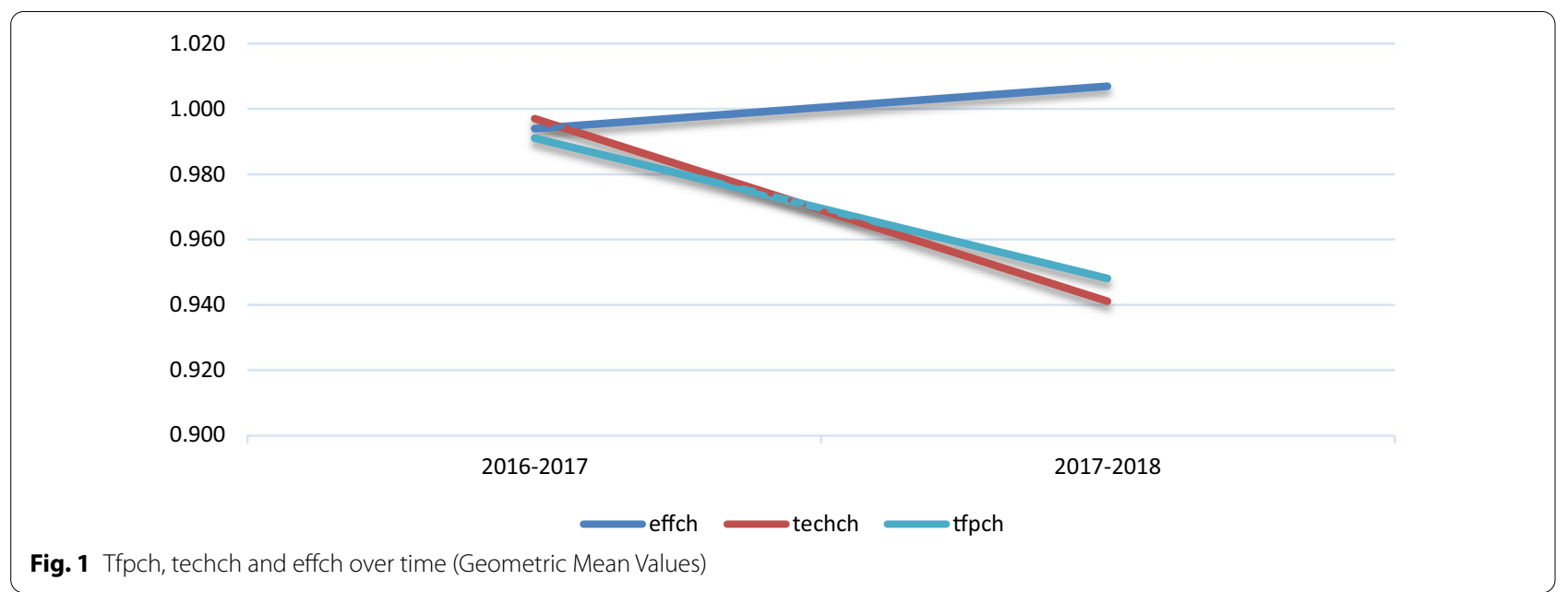

Table 6 Different models for internal validity check

\begin{tabular}{llllllllllllllllll}
\hline $\begin{array}{l}\text { Models/ } \\
\text { Variables }\end{array}$ & Out1 & Out2 & Out3 & Out4 & Out5 & Out6 & Out7 & Out8 & Out9 & Out10 & Out11 & Out12 & Inp1 & Inp2 & Inp3 & Inp4 \\
\hline M0 & X & X & X & X & X & X & X & X & X & X & X & X & X & X & X & X \\
M1 & X & X & X & X & X & X & X & X & X & X & X & X & & X & X & X \\
M2 & X & X & X & & & X & X & X & X & X & X & X & X & X & X & X \\
M3 & X & X & & X & X & X & X & & X & & X & X & X & & X \\
\hline
\end{tabular}

Table 7 Spearman rank correlation (model internal validity test-total productivity)

\begin{tabular}{lllll}
\hline & tfpch (M0) & tfpch (M1) & tfpch (M2) & tfpch (M3) \\
\hline tfpch (M0) & 1.000 & $0.896^{* *}$ & $0.951^{* *}$ & $0.766^{* *}$ \\
$\operatorname{tfpch}(\mathrm{M} 1)$ & $0.896^{* *}$ & 1.000 & $0.862^{* *}$ & $0.814^{* *}$ \\
$\operatorname{tfpch}(\mathrm{M} 2)$ & $0.951^{* *}$ & $0.862^{* *}$ & 1.000 & $0.708^{* *}$ \\
$\operatorname{tfpch}(\mathrm{M} 3)$ & $0.766^{* *}$ & $0.814^{* *}$ & $0.708^{* *}$ & 1.000 \\
\hline
\end{tabular}

${ }^{* *}$ Correlation is significant at the 0.01 level (2-tailed). N: 155

The first model (MO) considers all inputs and outputs, the second model (M1) excludes the input variable "Number of Managers", the third model (M2) excludes the output variables "Chronic Disease Cases" and "Emergencies", while the fourth model (M3) excludes the input variables "Number of Managers" and "Number of nonmedical staff" and the output variables "Test Mantoux", "Dental Procedures" and "Transcriptions".

After estimating the total productivities of the 155 health centres, under the input-oriented MPI DEA, the Spearman's rank correlation coefficients were calculated for the four different models (Table 7).
Table 8 Spearman rank correlation (model external validity test-productivity of each period)

\begin{tabular}{lcl}
\hline & tfpch (period1) & tfpch (period2) \\
\hline tfpch (period1) & 1.000 & $-0.250^{* *}$ \\
tfpch (period2) & $-0.250^{* *}$ & 1.000 \\
\hline
\end{tabular}

${ }^{* *}$ Correlation is significant at the 0.01 level (2-tailed). N: 155

The Spearman's rank correlation tests for internal validity show statistically significant correlations between the different model specifications.

To subject the analysis to an external validity test, the Spearman's rank correlation test between the calculated total productivities over the two periods was performed (Table 8).

The Spearman's rank correlation tests for external validity show a low but statistically significant correlation between periods.

The Spearman's rank coefficients re-ensure strong external and internal validity for the model. 


\section{Discussion}

The dataset was provided by the Ministry of Health and covered the years 2016, 2017 and 2018. Attempts were made to collect data for all 207 health centres of Greece, as well as financial data for the health centres, which would have been used as inputs for this paper and would have contributed to the evaluation of the total productivities and efficiencies of the health centres. The financial resources of each health centre constitute a vital parameter in the evaluation of their efficiencies and productivities, since financial resources determine health centres' resources for operating and providing health services. Unfortunately, data on costs and expenditures for the health centres were missing. Still, since that health centres are labour-intensive units, the total staff employed and occupied was used as inputs for the estimation of the total productivities and efficiencies. It is recommended that the Greek government start gathering financial data to estimate the total productivity and efficiency of primary health care [27]. In addition, 52 health centres were excluded from this paper due to lack of data, mainly due to the change in the system that the data were collected in 2016.

\section{Conclusion}

In this paper, the nonparametric DEA method, along with the MPI, was used to estimate the productivity change during the period 2016-2018. Moreover, after the estimation of productivity of each health centre for the years 2016, 2017 and 2018, as well as the change in productivity of each health centre over time, the factors that contributed most were estimated, shedding light on the changes in technical efficiency and technology for the health centres during 2016-2018.

Meaningful results were extracted by calculating the number of health centres that improved their productivity, regressed in productivity or remained constant through 2016-2018. Additionally, productivity evaluation is critical since it provides important information about the viability and efficiency of each health centre and shows the overall growth and progress of primary health care [11].

In a previous paper for health centres in Greece for 2018, a Tobit regression analysis was employed to investigate if there was a correlation between their productivity levels and the health region to which they belonged: "since they operate in district areas with differences and peculiarities in many aspects, such as concentration of people in their region, an environmental factor which may affect the health of the overall population, availability to employ specialized workforce and hospitals nearby health centres that it may affect" $[12,28]$.The study showed that the efficiency of the health centres was not affected by the health region to which they belong [19]. Moreover, the average efficiency of the 198 Health Centers for 2018 was 0.916 , but the study did not consider panel data. Extensive research should be conducted to investigate exogenous factors that may affect the efficiency and productivity of health centres such as demographic, socioeconomic, and community criteria, as well as environmental factors. Moreover, meaningful results can be extracted by evaluating the efficiency and productivity of TOMY after the first years of their operation.

Greece's economic crisis affected the country's primary health care, leading to a decline in the overall efficiencies and productivity of health centres. The first years of the reform did not have the expected results in primary health care. The reform fell into a lack of planning and physical resources, which, along with the missing guidelines, the absence of organization and referral systems led to people's dissatisfaction. However, the gradual reshaping of the primary health care system and the initiation of the population in primary health care services are expected to give encouraging results in the near future. The reforms created a framework in which significant steps can be made to improve the primary health care system.

This paper may contribute to improving health centres' efficiency and productivity. Furthermore, valuable results can be extracted for the National Health Care System to match available resources depending on each centre's needs, as well as for manager planners and stakeholders in primary health care.

It is globally accepted that health systems with strong people-centred, continuous, comprehensive and coordinated PHC are more efficient [8]. To achieve better results, it is strongly recommended for the government and stakeholders to better distribute the personnel occupied in health centres to introduce continuous professional development among the specialized workforce. In addition, health centres that face inefficiencies should take as an example from the efficient centres. Achieving the above will lead people to embrace the primary health care system and utilize health centres and TOMY services, laying the foundation for the success of the reform.

The estimation of total productivities and efficiencies of health centres were calculated using DEAP version 2.1 for Windows by Coelli (1996). Statistics were performed by using the IBM SPSS program.

\section{Abbreviations}

WHO: World Health Organization; OECD: Organization for Economic Cooperation and Development; PEDY: National Primary Health Care Network; ESY: Regional Health Care Authorities; TOMY: Local health unit; DEA: Data envelopment analysis; DMU: Decision making unit; CRS: Constant return to scale; VRS: Variable return to scale; MPI: Malmquist productivity index; Effch: 
Efficiency change; Techch: Technology change; Pech: Pure efficiency change; Sech: Scale efficiency change; Tfpch: Total factor productivity change.

\section{Supplementary Information}

The online version contains supplementary material available at https://doi. org/10.1186/s12962-021-00326-z.

Additional file 1: Includes detailed table with Descriptive Statistics of inputs and outputs for the years 2016, 2017 and 2018.

Additional file 2: Includes detailed table with Malmquist Productivity Index results for periods 2016-2017, 2017-2018 and overall results for both periods

\section{Acknowledgements}

Not applicable.

\section{Authors' contributions}

All authors read and approved the final manuscript.

\section{Funding}

No funding was received.

\section{Availability of data and materials}

The data that support the findings of this study are available from Bi-health (Ministry of Health) but restrictions apply to the availability of these data, which were used under license for the current study, and so are not publicly available. Data are however available from the authors upon reasonable request and with permission of Ministry of Health.

\section{Declarations}

Ethics approval and consent to participate Not applicable.

\section{Consent for publication}

Not applicable.

\section{Competing interests}

The authors declare that they have no competing interests.

\section{Author details}

${ }^{1}$ Faculty of Health Sciences, University of Peloponnese, Tripoli, Greece. ${ }^{2}$ Faculty of Finance and Statistics, University of Piraeus, Piraeus, Greece.

\section{Received: 9 July 2021 Accepted: 26 October 202}

Published online: 02 November 2021

\section{References}

1. World Health Organization. Roadmap to monitoring health services delivery in the WHO European Region. WHO Regional Office for Europe; 2017

2. Androutsou L, Geitona M, Yfantopoulos J. Measuring efficiency and productivity across hospitals in the regional health authority of Thessaly, Greece. J Health Manage. 2011;13(2):121-40.

3. OECD/European Observatory on Health Systems and Policies. Greece: Country Health Profile 2017, State of Health in the EU. OECD Publishing, Paris/European Observatory on Health Systems and Policies. Brussels; 2017. Doi: https://doi.org/10.1787/9789264283404-en

4. OECD/European Observatory on Health Systems and Policies. Greece: country health profile 2019, state of health in the EU. Brussels: OECD Publishing, Paris/European Observatory on Health Systems and Policies; 2019

5. Tountas $Y$, Karnaki P, Pavi E. Reforming the reform-the Greek national health system in transition. HealthPolicy. 2002;62(1):15-29. https://doi. org/10.1016/S0168-8510(01)00217-2.
6. Economou C, Giorno C. Improving the Performance of the public health care system in Greece. OECD Economics Department Working Papers. 2009. p. 722. Doi: https://doi.org/10.1787/221250170007.

7. Lionis C, Symvoulakis E, Markaki A, Vardavas C, Papadakaki M, Daniilidou $\mathrm{N}$, et al. Integrated primary health care in Greece, a missing issue in the current health policy agenda: a systematic review. Int J Integr Care. 2009. https://doi.org/10.5334/ijic.322.

8. Myloneros T, Sakellariou D. The effectiveness of primary health care reforms in Greece towards achieving universal health coverage: a scoping review. BMC Health Serv Res. 2021. https://doi.org/10.1186/ s12913-021-06678-9.

9. Emmanouilidou M. The 2017 Primary Health Care (PHC) reform in Greece: improving access despite economic and professional constraints? Health Policy. 2021;125:290-5. https://doi.org/10.1016/j.healthpol.2020.12.017.

10. Seiford LM, Thrall RM. Recent developments in DEA: the mathematical programming approach to frontier analysis. J Econom. 1990;46(1-2):7-38. https://doi.org/10.1016/0304-4076(90)90045-U.

11. Dimas G, Goula A, Soulis S. Productive performance and its components in Greek public hospital. Oper Res. 2012;12(1):15-27. https://doi.org/10. 1007/s12351-010-0082-2.

12. Worthington A. Frontier efficiency measurement in health care: a review of empirical techniques and selected applications. Med Care Res Rev. 2004;61(2):135-70

13. Debreu $\mathrm{G}$. The coefficient of resource utilization. Econometrica. 1951:19:272-92.

14. Koopmans TC. Activity analysis of production and allocation. New York: Wiley; 1951. p. 33-97.

15. Farrell MJ. The measurement of productive efficiency first published: 1957. J R Stat Soc Ser A (General). 1957. https://doi.org/10.2307/2343100.

16. Hollingsworth B, Dawson PJ, Maniadakis N. Efficiency measurement of health care: a review of non-parametric methods and applications. Health Care Manag Sci. 1999;2(3):161-72.

17. Charnes A, Cooper WW, Rhodes E. Measuring the efficiency of decision making units. Eur J Oper Res. 1978;2(6):429-44.

18. Banker RD, Charnes A, Cooper WW. Some models for estimating technical and scale inefficiencies in data envelopment analysis. Manage Sci. 1984;30(9):1078-92

19. Trakakis A, Nektarios M, Tziaferi S, Prezerakos P. Measuring technical efficiency of health centers in Greece: a data envelopment analysis application for the primary health system of Greece. Eur Res Stud J. 2021;XXIV(1):1333-53.

20. Mohammadi A, Ranaei H. The application of DEA based Malmquist productivity index in organizational performance analysis. Int Res J Financ Econo. 2011:62:68-76.

21. Hanksever C. Service management and operations. Prentice Hall; 2000.

22. Fried HO, Lovell CAK, Schmidt SS. The measurement of productivity efficiency: techniques and applications. Oxford University Press; 1993. p. $3-67$.

23. Fried HO, Lovell CAK, Schmidt SS. The measurement of productive efficiency and productivity growth. Oxford University Press; 2008. https://doi. org/10.1093/acprof:oso/9780195183528.001.0001.

24. Grosskopf S. Efficiency and productivity. In: Fried HO, Lovell CAK, Schmidt SS, editors. The measurement of productive efficiency: techniques and applications. New York: Oxford University Press; 1993. p. 94-160.

25. Lovell CAK. Production frontiers and productive efficiency in the measurement of productive efficiency: techniques and applications. In: Fried HO, Lovell CAK, Schmidt SS, editors. The measurement of productive efficiency: techniques and applications. New York: Oxford University Press; 1993. p. A:3-67.

26. Hollingsworth B. Non-parametric and parametric applications measuring efficiency in health care. Health Care Manag Sci. 2003;6(4):18-203.

27. Xenos P, Yfantopoulos J, Nektarios M, Polyzos N, Tinios P, Constantopoulos A. Efficiency and productivity assessment of public hospitals in Greece during the crisis period 2009-2012. Cost Eff Resour Alloc. 2017. https:// doi.org/10.1186/s12962-017-0068-5

28. Fragkiadakis G, Doumpos M, Zopounidis C, Germain C. Operational and economic efficiency analysis of public hospitals in Greece. Ann Oper Res. 2016:247:787-806. 
29. Daouia A, Simar L. Nonparametric efficiency analysis: a multivariate conditional quantile approach. J Economet. 2007;140(2):375-400. https:// doi.org/10.1016/j.jeconom.2006.07.002.

30. Johnson PTJ, Ostfeld RS, Keesing F. Frontiers in research on biodiversity and disease. Ecol Lett. 2015;18:1119-33. https://doi.org/10.1111/ele. 12479.

31. Simar $L$, Wilson PW. Two-stage efficiency analysis for Stata. FAU Discussion Papers in Economics. 2018.

32. Coelli TJ. A guide to DEAP version 2.1: A data envelopment analysis (Computer) program. CEPA Working Paper 96/08. University of New England, Armidale; 1996.

33. Majumdar S, Asgari B. Performance analysis of listed companies in the UAE-Using DEA Malmquist index approach. Am J Oper Res. 2017;7:13351. https://doi.org/10.4236/ajor.2017.72010.

34. Ramakrishnan M, Chandrasekaran R. Global economic crisis and productivity changes of banks in India: A DEA-MPI analysis. Int J Data Envel Anal Oper Res. 2014;1(3):40-8. https://doi.org/10.12691/ijdeaor-1-3-1.

35. Färe R, Grosskopf $S$, Norris M, Zhang Z. Productivity growth, technical progress, and efficiency change in industrialized countries. Am Econ Rev. 1994:84:66-83.

36. Nghiem S, Coelli T, Barber S. Sources of productivity growth in health services: a case study of queensland public hospitals. Econ Anal Policy. 2011;41(1):37-48

37. Grosskopf S. Some remarks on productivity and its decomposition. J Prod Anal. 2002;20:459-74.

38. Färe R, Grosskopf S. Modeling undesirable factors in efficiency evaluation: comment. Eur J Oper Res. 2004;157(1):242-5. https://doi.org/10.1016/ S0377-2217(03)00191-7.
39. Sarkis J, Talluri S. A model for strategic supplier selection. J Supply Chain Manag. 2002;38(4):18-28.

40. Sarkis J. Preparing your data for DEA. In: Zhu J, Cook WD, editors. Modeling data irregularities and structural complexities in data envelopment analysis, vol. 17. 1st ed. Boston, MA: Springer; 2007. p. 305-20. https://doi. org/10.1007/978-0-387-71607-7_17

41. Reddy GT. Comparison and correlation coefficient between CRS and VRS models of OC mines. Int J Ethics Eng Manage Educ. 2015;2(1):2348-4748.

42. Lu WC, Liu TK. Malmquist indices of R\&D productivity growth in Taiwanese IC-design industry. Glob J Bus Res. 2010;4(1):105-14.

43. Ganley JA, Cubbin JS. Public sector efficiency measurement: applications of data envelopment analysis. North-Holland: Elsevier; 1992.

44. Valdmanis V. Sensitivity analysis for DEA models: an empirical example using public vs N.F.P Hospitals. J Public Econ. 1992;4:185-205.

45. Parkin D, Hollingsworth B. Measuring production efficiency of acute hospitals in Scotland, 1991-94: validity issues in data envelopment analysis. Appl Econ. 1997;29(11):1425-33.

46. Maniadakis N, Kotsopoulos N, Prezerakos P, Yfantopoulos J. Measuring intra-hospital clinic efficiency and productivity: application to a Greek University General Hospital. Eur Res Stud J. 2008;6(1-2):95-110.

\section{Publisher's Note}

Springer Nature remains neutral with regard to jurisdictional claims in published maps and institutional affiliations.
Ready to submit your research? Choose BMC and benefit from:

- fast, convenient online submission

- thorough peer review by experienced researchers in your field

- rapid publication on acceptance

- support for research data, including large and complex data types

- gold Open Access which fosters wider collaboration and increased citations

- maximum visibility for your research: over 100M website views per year

At BMC, research is always in progress.

Learn more biomedcentral.com/submissions 